\title{
Anabases
}

ANABASES Traditions et réceptions de l'Antiquité

$24 \mid 2016$

Varia

\section{T. Power \& R. K. Gibson (éd.), Suetonius the Biographer. Studies in Roman Lives}

Olivier Devillers

\section{(2) OpenEdition}

Journals

Édition électronique

URL : http://journals.openedition.org/anabases/5785

DOI : 10.4000/anabases.5785

ISSN : 2256-9421

Éditeur

E.R.A.S.M.E.

Édition imprimée

Date de publication : 10 novembre 2016

Pagination : 360-361

ISSN : 1774-4296

\section{Référence électronique}

Olivier Devillers, «T. Power \& R. K. Gibson (éd.), Suetonius the Biographer. Studies in Roman Lives »,

Anabases [En ligne], 24 | 2016, mis en ligne le 15 novembre 2016, consulté le 23 septembre 2020.

URL : http://journals.openedition.org/anabases/5785; DOI : https://doi.org/10.4000/anabases.5785

Ce document a été généré automatiquement le 23 septembre 2020.

(c) Anabases 


\title{
T. Power \& R. K. Gibson (éd.), Suetonius the Biographer. Studies in Roman Lives
}

\author{
Olivier Devillers
}

\section{RÉFÉRENCE}

T. Power \& R. K. Gibson (éd.), Suetonius the Biographer. Studies in Roman Lives, Oxford, Oxford University Press, 2014, $338 \mathrm{p}$.

70 dollars /isbn 978-0-19-969710-6

1 Premier ouvrage collectif en anglais sur Suétone, issu pour l'essentiel d'un colloque qui s'est tenu à Manchester en 2008, ce volume aborde l'originalité du biographe sous différents aspects: style, contenu, composition, réception... Après un chapitre introductif, qui, en s'appuyant sur une riche bibliographie, expose ce propos (T. Power), une première partie, transversale, sur la construction des Vies, rassemble trois articles. D. Hurley épingle les problèmes d'organisation que posait le choix d'une présentation par rubriques (per species), bien adaptée surtout aux règnes longs, marqués par de grandes réalisations. C. Damon examine les diverses fonctions des citations d'empereurs: comme substituts de sententiae, pour souligner des thématiques ou comme vecteurs d'ironie. T. Power s'attache à la manière dont se termine chaque Vie suétonienne, souvent en écho les unes aux autres; les comparaisons et contrastes auxquels conduit le procédé confirment à la fois la cohérence de l'ensemble de l'ouvrage et le jugement qui peut être porté sur chaque empereur.

2 Une deuxième partie réunit des contributions davantage ponctuelles. J. Henderson s'interroge, à partir des interactions avec la Vie d'Auguste (mais pas seulement), sur le statut de la Vie de César, à la fois in and out à l'intérieur du corpus des Vies. Au départ de la législation d'Auguste sur le mariage, R. Langlands voit dans le texte de Suétone divers indices qui suggèrent que, en dépit de ses intentions, cet empereur n'a pu avoir 
la maîtrise sur l'usage que les princes postérieurs ont fait de l'œuvre qu'il leur léguait. E. Gunderson oppose d'une part la volonté d'exemplarité attachée au personnage d'Auguste et, d'autre part, l'incapacité de son successeur, Tibère, à livrer lui-même une image exemplaire. Pour D. Hurley, le récit de la mort de Caligula est, en écho à sa carrière de ce prince, élaboré de manière à ce que son assassinat apparaisse comme une juste rétribution de ses actes tyranniques. En comparant la Vie de Titus avec celle des autres empereurs, et spécialement celle d'Auguste, W. J. Tatum souligne sa place dans la réflexion de Suétone sur ce qui fait un bon empereur; cette contribution est l'une de celles qui abordent le plus directement l'idéologie du biographe. Dans une perspective plus strictement littéraire, J.-M. Hulls, à partir de l'image du miroir, livre diverses observations sur la construction de la figure tyrannique de Domitien.

3 La troisième partie rassemble quatre articles qui sont moins directement liés aux Vies des Césars. R. Gibson compare la liste des figures littéraires retenues par Suétone pour son De Viris illustribus avec celles que mentionne Pline le Jeune dans ses Lettres; il met en évidence la manifestation de perspectives sociales dans les choix des deux auteurs ainsi que dans leur traitement de la matière, Suétone apparaissant en particulier plus sensible à l'idée d'une ascension sociale procurée par le talent littéraire. T. Power se consacre à un ouvrage perdu de Suétone, Les Courtisanes célèbres, remettant en question le caractère biographique que lui a souvent prêté la recherche; aux fins de sa démonstration, il présente les précédents d'un tel ouvrage dans la littérature grecque, en discute le seul fragment conservé et propose de nouveaux fragments. C'est à un autre ouvrage perdu, sur les spectacles (De Ludis scaenicis et circensibus?) que s'intéresse T.P. Wiseman, plus spécialement à un fragment connu par Diomède et à ce qu'il apporte à notre connaissance de l'histoire du théatre. J. Wood examine les raisons pour lesquelles, au début $\mathrm{du}$ ix ${ }^{\mathrm{e}} \mathrm{s}$., Eginhard a choisi Suétone comme modèle de sa Vie de Charlemagne; un motif pourrait notamment en être la bonne réputation dont, à travers les auteurs chrétiens (saint Jérôme, Isidore de Séville), mais aussi l'Histoire Auguste, le biographe jouissait alors au sein de l'intellitgensia carolingienne.

4 C'est sans doute un objectif de la plupart des études réunies ici que de faire apparaître l'implication de Suétone dans la composition et l'écriture de son œuvre. En ce sens, audelà de la diversité des articles qui le constituent, quelques idées traversent ce livre : la cohérence des Vies des Césars et la nécessité d'éclairer chaque vie à la lumière des autres, le rôle d'Auguste (voire de César) comme référence pour les princes ultérieurs, la pratique de l'intratextualité et de l'ironie... On relèvera aussi le recours fréquent à la comparaison avec Dion Cassius, presque à part égale avec le plus attendu Tacite, en vue de mieux comprendre la spécificité des choix de Suétone.

5 Au total, le volume parvient à mettre en lumière un auteur dont les biographies ne sont pas toujours autant utilisées qu'elles le devraient par les historiens, et n'ont peut-être pas non plus trouvé encore leur juste place dans les études consacrées à la littérature latine.

Une bibliographie (très complète), deux index (des passages cités, général). 


\section{AUTEURS}

\section{OLIVIER DEVILLERS}

Université Michel de Montaigne

oldevillers@orange.fr 